\title{
A FUNÇÃO SOCIAL DOS TRIBUNAIS DE CONTAS NO BRASIL NA ORDEM CONSTITUCIONAL
}

Ronaldo Chadid*

Resumo: A presente pesquisa destina-se ao estudo da função social dos Tribunais de Contas e o desenvolvimento de suas competências, com o escopo de superar a ideia do controle formal limitado aos aspectos inerentes à legalidade, buscando na Constituição Federal valores que propiciem uma atuação voltada para uma análise qualitativa do gasto do dinheiro público. A investigação foi realizada por meio de levantamentos bibliográficos acerca do tema e do estudo dos diplomas legais que regem e norteiam a atuação do controle externo. O método de abordagem utilizado foi o dedutivo, partindo de premissas teóricas passíveis de conclusão acerca da problemática levantada.

Palavras-chave: Controle, Tribunal de Contas, Constituição, função social, eficiência

\section{THE SOCIAL FUNCTION OF THE COURTS OF ACCOUNTS IN BRAZIL IN THE CONSTITUTIONAL ORDER}

\begin{abstract}
The present research is aimed at studying the social function of the Courts of Accounts and the development of their competencies, with the scope of overcoming the idea of formal control limited to aspects inherent in legality, seeking in the Federal Constitution values that provide a a qualitative analysis of public money spending. The research was carried out through bibliographical surveys about the subject and the study of the legal diplomas that govern and guide the performance of external control. The method of approach used was the deductive, starting from theoretical premises that can be concluded about the problematic raised.
\end{abstract}

Keywords: Control, Audit Office, Constitution, social role, efficiency

\section{Introdução}

A correta gestão da "coisa pública” traduz-se em medida primordial do modelo democrático-republicano do Estado Brasileiro e desafia o permanente aperfeiçoamento de mecanismos e instituições envolvidas no sistema de Controle da Administração Pública, dentre elas, a atuação das Cortes de Contas nas respectivas áreas de atribuições na Federação. 
Justifica-se e evidencia-se a relevância no tema proposto na medida em que a existência de um controle atuante significa o fortalecimento da Democracia e via de consequência, a garantia dos direitos fundamentais. Vale dizer, as expectativas da subsistência do Erário e da regular manutenção da máquina pública com a verificação correta da utilização do dinheiro público estão lançadas à responsabilidade dos Tribunais de Contas.

Objetiva-se com a pesquisa demonstrar a existência de uma função dos Tribunais de Contas, e tem-se por escopo especificamente, explanar o sistema de controle da Administração Pública, abordar o controle externo, estudar sua estrutura e competências, para ao final, identificar a função social dos Tribunais de Contas.

Nesse viés de implementação da verdadeira função social dos Tribunais de Contas é que se abordam as formas e instrumentos capazes de modificar o modo de sua atuação, com base no escopo que deve ter para nortear-lhe o princípio da eficiência. Eis, portanto, a contribuição que a presente pesquisa procura trazer para que, de fato, possa transformar o Tribunal de Contas em Órgão participativo e decisivo no desenvolvimento do país e na consolidação do Estado Social de Direito, que deve levar à sociedade a melhor e mais eficiente política pública possível, diante das possibilidades reais que o orçamento pode proporcionar.

A metodologia utilizada foi a bibliográfica exploratória, pautada em doutrinas e demais trabalhos científicos sobre a tema, com abordagem dedutiva sobre o tema, partindo das premissas necessárias para responder a problemática em questão.

\section{O controle da administração pública}

Reconhecido por princípio fundamental da Administração Pública, o Controle pode ser definido como “conjunto de mecanismos jurídicos e administrativos por meio dos quais se exerce o poder de fiscalização e de revisão da atividade administrativa em qualquer das esferas de Poder.” (CARVALHO FILHO, 2012, p. 929)

De efeito, impensável coligir estrutura de princípios balizantes da atuação do administrador, sem em contraponto, fiscalizar e revisar a atuação dos gestores públicos.

Dentre as várias espécies e classificações de controle, em uma primeira cisão estrutural, temos o controle político e o administrativo. O primeiro, exercido estruturalmente entre os Poderes, cuja repartição e entrelaçamento dá origem ao que se chama de “controle de 


\section{A FUNÇÃO SOCIAL DOS TRIBUNAIS DE CONTAS NO BRASIL NA ORDEM CONSTITUCIONAL}

freios e contrapesos” expressão oriunda do direito norte-americano checkand balances (LENZA, 2008, p. 73). A exemplo, temos o controle exercido pelo Executivo sobre o Legislativo através do veto político por alegação de contrariedade ao interesse público (art. 66, $\left.\S 1^{\circ}, \mathrm{CF}\right)$ e aquele exercido pelo Legislativo e Executivo sobre o Judiciário quando os integrantes das Cortes de Superposição (art. 101, parágrafo único) são aprovados e nomeados por aqueles.

Pensa-se que justamente neste propósito é que às Funções Orgânicas do Estado Brasileiro não se talhou a característica da autonomia, como preferiu fazer o Constituinte Originário ao definir a distribuição de poder político, administrativo e financeiro aos Entes de Federação.

Tal entrelaçamento de controle é importante na esfera política, visto que justamente no campo macroestrutural, os Poderes com funções orgânicas: criadora e fiscalizadora (Legislativo), gerencial (Executivo) e pacificadora (Judiciário) dão a estabilidade necessária para atingimento dos objetivos colimados pelo detentor primitivo do poder - o povo (art. $1^{\circ}$, parágrafo único, CF).

Tratando-se de controle, não se pode olvidar daquele exercido pelo detentor da res pública: o povo. Neste contexto, temos o controle social fundamentado no modelo republicano, ganhando especial destaque com a aprovação da Lei Federal $n^{\circ} 12.527$, de 18 de novembro de 2011, a qual entrou em vigor em maio de 2012, regulamentando o direito de livre acesso às informações sob tutela do poder público, previsto no artigo $5^{\circ}$ da Constituição Federal, consolidando o regime democrático do país, ampliando a participação cidadã e fortalecendo os instrumentos de controle da gestão pública.

Quanto ao controle administrativo, este situa-se num campo mais pragmático e concreto, vez que "pretende alvejar os órgãos incumbidos de exercer uma das funções do Estado - a função administrativa” (CARVALHO FILHO, 2012, p. 929).

É da essência deste último, a preocupação com a regular movimentação da máquina pública e as suas consequências, já que decorre das ações governamentais a dignificação da pessoa humana através das prestações mínimas existenciais pelo Estado, bem como as relações internacionais que associa a capacidade de gestão do país aos riscos para pretensos acordos internacionais.

Neste aspecto, por mais que o controle administrativo desenvolva-se em nível mais específico que o político, a má atuação dos órgãos incumbidos do primeiro tem o condão de 
atingir toda estrutura política do país. Ou seja, atuam em campos distintos, mas são de importância elementar para o Estado.

Em apertada síntese, para não se desviar dos objetivos deste artigo, temos ainda no campo das classificações, o controle nominado pelo Poder que o exerce, e, partindo deste parâmetro, outra divisão: se interno ou externo.

Feitas tais considerações, passa-se ao exame específico do Controle AdministrativoFinanceiro Externo exercido pelos Tribunais de Contas (art. 71, CF).

3. O controle externo

Para análise e alcance da missão constitucional dos Tribunais de Contas, necessário o estudo minucioso do sistema de controle externo nos moldes delineados pela Constituição Federal, mormente no tocante à explanação sobre a posição constitucional e a natureza jurídica dos tribunais de contas, distinguindo sua atuação daquela que é afeta ao poder legislativo.

Consoante determinação inserta no caput do artigo $70^{1}$, a fiscalização contábil, orçamentária, financeira, operacional e patrimonial, será exercida pelo Congresso Nacional, o que, pelo Princípio da Simetria, conduz ao Poder Legislativo de cada ente. Entretanto, no artigo seguinte $^{2}$, determinou o poder constituinte originário, que o controle externo será de incumbência do Congresso Nacional, mas com o auxílio do Tribunal de Contas de União, passando a discriminar a atuação e a competência de cada um.

Vislumbra-se, portanto, a existência de atuações distintas e coordenadas, entre poder legislativo e tribunais de contas, como bem explica a doutrina de Benjamin Zymler (2006, p. 264):

O controle externo exercido pelo Poder Legislativo desdobra-se em duas vertentes: o controle político, realizado pelas Casas Legislativas, e o controle técnico, que abrange a fiscalização contábil, financeira e orçamentária, exercido com o auxílio do Tribunal de Contas da União.

\footnotetext{
${ }^{1}$ Art. 70. A fiscalização contábil, financeira, orçamentária, operacional e patrimonial da União e das entidades da administração direta e indireta, quanto à legalidade, legitimidade, economicidade, aplicação das subvenções e renúncia de receitas, será exercida pelo Congresso Nacional, mediante controle externo, e pelo sistema de controle interno de cada Poder.

${ }^{2}$ Art. 71. O controle externo, a cargo do Congresso Nacional, será exercido com o auxílio do Tribunal de Contas da União, ao qual compete : (...)
} 
Como enfatizado, o controle político e técnico têm diferentes momentos e foco de atuação. Entretanto, não são dissociados, e sim coordenados. Toma-se, como exemplo, o exercício do controle externo político exercido no julgamento das contas anuais (Presidente, Governador e Prefeitos, no caso do Poder Executivo). O julgamento é realizado pelo poder legislativo de cada ente, abordando as chamadas contas de governo. Entretanto, antes do julgamento pelo poder legislativo, as contas passam pelo crivo técnico do Tribunal de Contas, consubstanciado no parecer prévio (fase técnica).

Com efeito, o parecer prévio sobre as Contas é apreciado e julgado pelo Congresso Nacional (no caso do Presidente da República), pelas Assembleias Legislativas (no caso dos Governadores); e, pelas Câmaras Municipais (no caso dos Prefeitos). Oportunamente, são confrontados os gastos públicos com a vontade popular, consubstanciada na Lei de Diretrizes Orçamentárias e na Lei Orçamentária Anual, todas aprovadas pelo Poder Legislativo respectivo. Há que se observar também, se os dispêndios do erário guardam conformidade com as determinações insertas na Lei de Responsabilidade Fiscal.

Destarte, não pode o controle externo político prescindir de sua vertente técnica, sendo-lhe estreitamente vinculado. Daí a concepção de uma instância de controle independente, o controle externo dito técnico, personificado pelos Tribunais de Contas, dedicando-se à fiscalização contábil, orçamentária, financeira, patrimonial e operacional, auxiliando o controle político empreendido pelo Poder Legislativo (BEZERRA).

Evidente, portanto, que o auxílio ${ }^{3}$ prestado pelos Tribunais de Contas não conduz à ideia de dependência e vinculação ao poder legislativo, ao reverso, os dispositivos constitucionais acerca da matéria, reafirmam a posição independente das Cortes de Contas, como elucida Jorge Ulisses Jacoby Fernandes (2012, p. 168):

A Constituição Federal, em artigo algum utiliza a expressão de “órgão auxiliar”; dispõe que o Controle Externo do Congresso Nacional será exercido com o auxílio do Tribunal de Contas; a sua função, portanto,

\footnotetext{
${ }^{3}$ Como bem enfatiza Evandro Martins Guerra (2012, p. 148-149): “O Tribunal de Contas não possui natureza de órgão auxiliar pelo fato de possuir atribuições de cooperação com o controle externo exercido pelo Poder Legislativo, pois auxiliar é aquele que apenas auxilia, ajuda, subsidia, acode, socorre. Trata-se de adjetivo dito à pessoa associada a outra, para ajuda-la em suas funções, possuindo, portanto, papel secundário de menor relevância naquela atividade. Trata-se de uma falácia, uma contumélia irremissível, um sofisma repetido por aqueles que desconhecem o papel institucional das Cortes de Contas. Definitivamente, o termo auxílio, como prescrito no dispositivo constitucional, deve ser interpretado no sentido de fortalecimento do pretório, i.e., o exercício do controle é realizado por meio da execução de competências próprias, exclusivas, isto é, não se admite implementação do controle em a sua devida participação.
} 
é de exercer o controle financeiro e orçamentário da Administração em auxílio ao poder responsável, em última instância, por essa fiscalização. Tendo em vista que a própria constituição assegura ao Tribunal de Contas as mesmas garantias de independência do Poder Judiciário, impossível considerá-lo subordinado ao Legislativo ou inserido na estrutura do Legislativo. Se a função é de atuar em auxílio ao legislativo, sua natureza, em razão das próprias normas da constituição é a de órgão independente, desvinculado da estrutura de qualquer dos três poderes. A nosso ver, por conseguinte, o Tribunal de Contas configura instituição estatal independente.

Acerca do caráter ímpar das Cortes de Contas no Estado Democrático de Direito, e reforçando a autonomia, imprescindibilidade e a posição constitucional das Cortes de Contas, manifesta-se a doutrina de José Ricardo Parreira de Castro (2015, p. 54-55):

Trata-se, pois, de órgãos autônomos, de extração constitucional, cuja missão é o exercício do controle externo, através do desempenho das competências constantes no rol dos incisos I a IX do art. 71 da CRFB. Em determinado casos, como por exemplo, os casos dos incisos I (contas do Chefe do Poder Executivo), IV (realização de auditorias, por iniciativa própria ou por provocação do Poder Legislativo), VII (prestação de informações ao Poder Legislativo), X (sustação da execução de ato administrativo impugnado, XI (representação à Poder), e $\S 1^{\circ}$ (sustação de execução de ato impugnado) a função de "auxílio" pode ser percebida com maior vigor, posto que o desenrolar destas competências pode ocorrer por provocação do Poder Legislativo ou, ainda, o desfecho da atuação do Tribunal de Contas se dará no âmbito do Poder Legislativo. Nos demais casos, porém, se avulta a atuação autônoma dos Tribunais de Contas, na medida em que o exercício de competência será deflagrado pela própria Corte de Contas e, mais do que isso, o seu esgotamento também ocorrerá na internalidade da Corte. (...) Em outros termos: há uma finalidade própria aos processos de contas (e no próprio controle externo), incapaz de ser atendida por outros meios de atuação estatal, como a atuação judicial e/ou parlamentar. Tal constatação nos leva a concluir pela imprescindibilidade das Cortes de Contas, já que, inexistente o sistema brasileiro de controle externo, os demais órgãos existentes não seriam capazes de atender às finalidades públicas que se associam à atividade de controle externo da Administração Pública.

Consoante depreende-se os ensinamentos aqui esposados, o sistema de controle externo brasileiro encontra-se perfeitamente delineado na Constituição Federal de 1988, e esse mister é atribuído ao Poder Legislativo e ao Tribunal de Contas. O primeiro exerce o controle político e o segundo, o controle técnico. São as Cortes de Contas, portanto, órgãos de extração 
constitucional com autonomia administrativa e financeira, cujas atividades são imprescindíveis para a manutenção do Estado Democrático de Direito.

Diante do posicionamento constitucional dos Tribunais de Contas, e identificado o seu papel no controle externo, é de extrema relevância conhecer a estrutura e atribuições do órgão.

\section{Composição e competências dos Tribunais de Contas no Brasil:}

Tratando-se de composição e estruturação dos Tribunais de Contas, é imperioso destacar que a Constituição Federal de 1988 aborda as disposições gerais para o Tribunal de Contas da União, que deverá ser composto por nove ministros. Entretanto, deixa explícita a aplicação do Princípio da Simetria, conforme esclarece Jorge Ulisses Jacoby Fernandes (2012, p. 777):

No Brasil, encontra-se implícita, na Constituição Federal, a ideia de estruturação sistêmica da atividade de controle. (...) O Tribunal de Contas da União constitui o paradigma federal de controle, devendo as normas constitucionais pertinentes serem aplicadas, no que couber, aos Tribunais de Contas dos Estados e do Distrito Federal. Duas regras foram compulsoriamente definidas para os Tribunais de Contas das unidades federadas: compete à constituição estadual dispor sobre os Tribunais de Contas, os quais adiantou o constituinte, devem ser integrados, necessariamente, por sete conselheiros.

A escolha dos Ministros dos Tribunais de Contas deve atender a requisitos mínimos, sendo-lhes garantidas as mesmas prerrogativas, impedimentos, vencimentos e vantagens dos Ministros do STJ, como bem explica Celso Antônio Bandeira de Mello (2012, p. 960):

O Tribunal de Contas, órgão cujo poder de administração própria é análogo ao dos Tribunais de Justiça (órgãos do Poder Judiciário), é integrado por nove membros, denominados Ministros. São requisitos de investidura nestes cargos ter mais de 35 e menos de 65 anos de idade, idoneidade moral e reputação ilibada, dispor de notórios conhecimentos jurídicos, contábeis, econômicos, financeiros ou de administração pública e contar com mais de dez anos de exercício de função ou efetiva atividade profissional exigente da espécie de conhecimentos referidos (art. 73 e $\S 1^{\circ}$ ). Aos titulares destes cargos são conferidas ou irrogadas as mesmas garantias, prerrogativas, impedimentos, vencimentos e vantagens dos Ministros do Superior Tribunal de Justiça $\left(\S 3^{\circ}\right.$ do art. 73). Portanto, gozam de vitaliciedade. 
Em apertada síntese, pode-se atestar a existência de um Tribunal de Contas da União (responsável pelo controle dos bens, dinheiros, e valores da esfera federal e sobre territórios federais, se houver); vinte e seis Tribunais de Contas de Estado; quatro Tribunais de Contas de Municípios (encarregados de fiscalizar as contas de todos os municípios dos estados da Bahia, Ceará, Goiás e Pará); dois Tribunais de Contas de Município, encarregados de fiscalizar as contas do Município de São Paulo e Rio de Janeiro; um Tribunal de Contas do Distrito Federal (MELLO, 2012, p. 960).

Sendo detentor de garantias de autonomia funcional, administrativa e financeira, idênticas a dos demais Tribunais do Judiciário, foram-lhe incumbidas funções que o identificam e o distinguem como uma estrutura política da soberania, no desempenho de diversas atribuições de proteção de direitos fundamentais (MELLO, 2012, p. 104).

Acerca das características das competências dos Tribunais de Contas, emprestemo-nos das lições de Helio Saul Mileski (2006, p. 100), que as classifica em próprias, exclusivas e indelegáveis:

$1^{\circ}$ Próprias: porque são peculiares aos procedimentos de controle. Tratase de competências que envolvem atividades autênticas de controle, com a finalidade de vigiar, acompanhar e julgar a regularidade dos atos e atividades financeira controlados.

$2^{\circ}$ Exclusivas: porque são competências constitucionais destinadas tãosomente para o Tribunal de Contas e não podem ser exercidas por nenhum outro órgão ou Poder, mesmo o Poder Legislativo.

$3^{\circ}$ Indelegáveis: porque são competências que envolvem atividade de controle da atividade financeira do Estado, sendo por isso de exercício privativo do Poder Público, cuja execução também é privativa do Tribunal de Contas, não podendo ser delegada a qualquer dos Poderes ou a outra organização, pública ou privada.

Com efeito, a Constituição Federal, em seus artigos 70 e 71, concedeu aos Tribunais de Contas diversas funções e competências, que a doutrina elenca em nove básicas (ZYMLER; ALMEIDA, 2005, p. 143-144):

a) função fiscalizadora com a competência de realizar auditorias e inspeções nos órgãos e entidades;

b) função judicante, na medida em que efetivamente realiza o julgamento de contas da atividade do Poder Público;

c) função sancionadora, multando os responsáveis pela prática de atos irregulares ou ilegais e determinando o ressarcimento dos prejuízos ao erário;

d) função pedagógica, no exercício da competência de emitir comunicações, recomendações e orientações; 
e) função consultiva, quando lhe compete emitir pareceres;

f) função informativa, no envio de informações ao Poder Legislativo, expedir alertas previstos na Lei de Responsabilidade Fiscal e divulgar dados sobre a atividade da Administração;

g) função normativa, ao editar normas de sua competência;

h) função ouvidora, no recebimento de denúncias;

i) função corretiva, quando fixa prazos para correção de irregularidades ou que sustem os atos impugnados.

As funções e atribuições dos Tribunais de Contas prestam-se na maioria dos casos, ao controle posterior de atos de gestão da Administração Direta e Indireta, em especial, em relação à análise dos aspectos de legalidade e regularidade dos atos administrativos executivos. De maneira mais contida também atua preventivamente como no caso do confronto das propostas das Leis Orçamentárias aos princípios norteadores da Administração Pública, (por exemplo, art. 78, § $2^{\circ}$ da Constituição do Estado de Mato Grosso do Sul).

Vale lembrar, que nos paradigmas atuais, não cabe aos Tribunais de Contas a verificação apenas da legalidade formal do ato. O grande desafio é superar a barreira da legalidade para aferir se o ato do administrador guarda conformidade com os princípios norteadores da administração. Esta a tratar do controle de mérito, conceito estreito com a legitimidade, ou seja, racionalidade nas despesas e nas prioridades da coletividade, bem como, a economicidade, assim entendido o binômio entre custo e benefício (FIGUEIREDO, 1991, p. 167-187). Superada essa evidência, passa-se ao estudo da função social dos Tribunais de Contas.

\section{FUNÇÃO SOCIAL DOS TRIBUNAIS DE CONTAS}

As transformações ocorridas nos Estados modernos ocidentais e que ocasionaram profundas alterações nos sistemas jurídicos, com a adoção do modelo de constitucionalização e codificação como base de toda estruturação e disciplina da vida em sociedade tem se mostrado reflexo do Estado de Direito Social, fazendo-se presente não somente no contexto jurídico, mas, sobretudo, na transformação do valor social positivado em políticas públicas que alcancem os anseios e necessidades da população.

Essa ideologia, ao mesmo tempo jusfilosófica e pragmática da ação do Estado, tem sido campo fértil para a efetiva afirmação do papel do Estado e dos Órgãos de Controle. 
Está absolutamente claro na Constituição e na legislação brasileira que os valores mais caros e importantes para o atual momento histórico estão contemplados nos textos normativos.

O art. $1^{\circ}$ da Constituição impõe que a República Federativa do Brasil e formada pela união indissolúvel dos Estados e Municípios e do Distrito Federal, constitui-se em Estado Democrático de Direito e tem como fundamentos a soberania, a cidadania, a dignidade da pessoa humana, os valores sociais do trabalho e da livre iniciativa, o pluralismo político, e que todo o poder emana do povo, que o exerce por meio de representantes eleitos ou diretamente. $\mathrm{O}$ art. $2^{\circ}$ contempla a tripartição de poderes. $\mathrm{O}$ art. $3^{\circ}$ determina como objetivos fundamentais da República Federativa do Brasil: construir uma sociedade livre, justa e solidária, garantir o desenvolvimento nacional, erradicar a pobreza e a marginalização e reduzir as desigualdades sociais e regionais, promover o bem de todos, sem preconceitos de origem, raça, sexo, cor, idade e quaisquer outras formas de discriminação. $\mathrm{O}$ art. $5^{\circ}$ dispõe que todos são iguais perante a lei, sem distinção de qualquer natureza, garantindo-se aos brasileiros e aos estrangeiros residentes no País a inviolabilidade do direito à vida, à liberdade, à igualdade, à segurança e à propriedade, da qual se seguem 78(setenta e oito) incisos e 4(quatro) parágrafos que abarcam dezenas de regras e valores que deveriam ser cumpridos pela sociedade e pelo Estado.

Em outros exemplos, como no Código Civil, valores como a socialidade, a eticidade e a boa-fé objetiva foram internalizados e passaram a ser paradigmas das situações nos casos concretos.

Se por um lado é absolutamente perceptível que o Estado, no desempenho de cada um de seus Poderes, não consegue plenamente cumprir com sua função social, por outro, possui mecanismos indicados na própria Constituição Federal para auxilia-lo nessa tarefa por meio dos Órgãos de Controle.

Dentre os Órgãos que exercem a função de auxílio no cumprimento das demandas sociais e das execuções dos programas governamentais temos os Tribunais de Contas, que fazem a defesa do indivíduo, do patrimônio público, dos valores sócias, por meio de mecanismos que procuram incrementar a transparência na gestão, combater o desperdício e a corrupção, e detectam e impõe a correção dos rumos de implementação/consolidação de políticas públicas que possam concretizar benefícios à sociedade.

As funções que constitucionalmente foram outorgadas aos Tribunais de Contas. No cumprimento dessas funções concentra-se a sua função social. 
Na Constituição do Império de 1824 não havia previsão da instauração de um órgão de fiscalização e controle, porém, a ideia de criação já vinha de tempos anteriores. Na França, indícios de uma espécie de fiscalização das contas ocorreu com o rei Luís IX (século XIII), com a instituição da Chambre de Comptes, encarregada de vigiar os gastos em seu reinado (BARROS, 1999, p. 223). Esta foi extinta com o advento da Revolução Francesa por ser considerada como pertencente ao Ancien Régime (SANTOS, 2005. p. 350). Ensina Lucivaldo Barros que a Chambre de Comptes influenciou a criação, em 1807, da Cour de Comptes, incumbida de analisar as contas a posteriori, uma vez que o exame prévio havia sido atribuído ao Ministério Ordenador da Despesa e ao da Fazenda (BARROS, 1999, p. 224).

Assim, o debate intelectual passou a ser considerado importante, mesmo que com a adoção da Constituição imperial outorgada. Sob a iniciativa dos senadores Visconde de Barbacena e José Inácio Borges, foi proposto projeto de lei para criação de um Tribunal de Exame de Contas, que teria, a exemplo do modelo francês, uma fiscalização posterior, o que foi rejeitado pelo senador Conde de Baependi, ex-Ministro da Fazenda (BARROS, 1999, p. 226).

Na Constituição de 1891 (art. 89), foi instituído o Tribunal de Contas, com a função de liquidar as contas da receita e despesa e verificar a sua legalidade, antes de serem prestadas ao Congresso, numa evidente atribuição meramente formal e, obviamente, aquém da função social que merecia exercer.

Na Constituição de 1934, em 13(treze) dispositivos há a menção da instituição “Tribunal de Contas” e, na Seção II, do Capítulo VI (Dos Órgãos de Cooperação nas Atividades Governamentais), do Título I (Da Organização Federal), tem sua previsão estabelecida juntamente com suas atribuições (arts. 99 a 102): a) acompanhará a execução orçamentária e julgará as contas dos responsáveis por dinheiros ou bens públicos, b) registro de contratos que interessarem à receita ou à despesa, c) verificação prévia de qualquer ato de Administração Pública de que resulte obrigação de pagamento ao Tesouro Nacional, ou por conta deste, d) a fiscalização financeira dos serviços autônomos, na forma prevista em lei, e) dar parecer prévio das contas anuais do Presidente da República. A localização topográfica do Tribunal de Contas foi determinada em Seção distinta do Poder Legislativo e as suas atribuições foram ampliadas, sendo que, a preocupação com o controle financeiro e orçamentário (prévio, concomitante, e posterior) passaram a ser o centro de sua função social. 
Na Constituição de 1937 há um retrocesso no trato da Corte de Contas, limitando a sua previsão em apenas dois artigos, sendo que, a sua competência é estabelecida num único dispositivo (art. 114): acompanhar, diretamente, ou por delegações organizadas de acordo com a lei, a execução orçamentária, e julgar das contas dos responsáveis por dinheiros ou bens públicos e da legalidade dos contratos celebrados pela União. A redação utilizada não dividiu a organização estatal, os direitos e as atribuições em Títulos, Capítulos ou Seções, pelo que, o Tribunal de Contas e todos os demais assuntos foram previstos em itens isolados.

Na Constituição de 1946 o Tribunal de Contas volta a ter destaque, tendo suas competências reestabelecidas e ampliadas mas, ainda assim, a sua função encontrava-se atrelada apenas a aspectos de legalidaade. A sua previsão institucional encontra-se no Capítulo II (Do Poder Legislativo), Seção VI (Do orçamento), onde também foram definidas suas competências (art. 77): a) acompanhar e fiscalizar diretamente, ou por delegações criadas em lei, a execução do orçamento, b) julgar as contas dos responsáveis por dinheiros e outros bens públicos, e as dos administradores das entidades autárquicas, c) julgar da legalidade dos contratos e das aposentadorias, reformas e pensões, d) registrar os contratos que, por qualquer modo, interessarem à receita ou à despesa, podendo o Tribunal de Contas suspender a execução do contrato até o pronunciamento do Congresso Nacional, e) Dar parecer prévio sobre as contas anuais do Presidente da República.

Na Constituição de 1967, pela primeira vez utiliza-se da expressão “controle externo” como competência exercida pelo Congresso Nacional, com o auxílio do Tribunal de Contas, compreendendo a apreciação das contas anuais do Presidente da República por meio de parecer prévio, o julgamento das contas dos administradores e demais responsáveis por bens e valores públicos, e o desempenho das funções de auditoria financeira e orçamentária sobre as contas das unidades administrativas dos três Poderes da União, que, para esse fim, deveriam remeter demonstrações contábeis ao Tribunal de Contas, a quem caberia realizar as inspeções que considerasse necessárias. Também concedeu competência para, de ofício ou mediante provocação do Ministério Público ou das auditorias financeiras e orçamentárias e demais órgãos auxiliares, verificar a ilegalidade de qualquer despesa, inclusive as decorrentes de contratos incumbiu a verificação da ilegalidade de qualquer despesa, inclusive as decorrentes de contratos, aposentadorias, reformas e pensões (arts. 71 a 73). Também incumbiu o Tribunal de 
Contas a elaborar do cálculo das quotas estaduais e municipais na repartição do produto da arrecadação dos impostos (art. 25, §1 ${ }^{\circ}$ )

A Emenda Constitucional n. 1 de 1969 atribuiu (art. 16) expressamente à Câmara de Municipal o exercício do controle externo com o auxílio do Tribunal de Contas, sendo este incumbido de elaborar o parecer prévio sobre as contas anuais do Prefeito, cuja decisão seria modificada pelo Legislativo mediante dois terços dos vereadores. Também manteve a incumbência na elaboração do cálculo das quotas estaduais e municipais na repartição do produto da arrecadação dos impostos (art. 25, §1º. Além dessas, manteve nos arts. 70 a 72 as atribuições da Constituição de 1967 que constavam nos arts 71 a 73.

Finalmente, na Constituição Federal de 1988 o Tribunal de Contas tem suas atribuições fortalecidas como instituição de controle externo. Em 23(vinte e três) dispositivos há menção sobre sua estrutura, competência e prerrogativas. Em 2(dois) artigos concentra-se o núcleo de suas competências de controle externo, atribuindo ao Tribunal de Contas nos arts. 70 e 71, a fiscalização contábil, financeira, orçamentária, operacional e patrimonial da União e das entidades da administração direta e indireta, quanto à legalidade, legitimidade, economicidade, aplicação das subvenções e renúncia de receitas; a apreciação das contas prestadas anualmente pelo Presidente da República, mediante parecer prévio; o julgamento das contas dos administradores e demais responsáveis por dinheiros, bens e valores públicos da administração direta e indireta, incluídas as fundações e sociedades instituídas e mantidas pelo Poder Público federal, e as contas daqueles que derem causa a perda, extravio ou outra irregularidade de que resulte prejuízo ao erário público; a apreciação, para fins de registro, a legalidade dos atos de admissão de pessoal, a qualquer título, na administração direta e indireta, bem como a das concessões de aposentadorias, reformas e pensões; a realização de inspeções e auditorias de natureza contábil, financeira, orçamentária, operacional e patrimonial, nas unidades administrativas dos Poderes Legislativo, Executivo e Judiciário; a fiscalização das contas nacionais das empresas supranacionais; a aplicação aos responsáveis, em caso de ilegalidade de despesa ou irregularidade de contas, as sanções previstas em lei, com força de título executivo extrajudicial (art. 75); e a competência para efetuar o cálculo das quotas dos fundos de participação na repartição de receitas (art. 161, parágrafo único). Além disso, impõe expressamente o dever de prestação de contas ao Tribunal de Contas a um rol extenso e abrangente de pessoas (art. 71), o que amplia o seu poder de fiscalização. 
Pela primeira vez, no núcleo dos aspectos passíveis de fiscalização foi expressamente fixado o elemento "economicidade”, o que ampliou as possibilidades de atuação do Tribunal de Contas. Anterior à Constituição de 1988 a adequação dos fatos à norma apenas sob seu aspecto de legalidade contribuíam para restringir a fiscalização aos atos administrativos sob seu aspecto formal. Com o advento da Emenda Constitucional n. 19, de 04 de junho de 1988, que acresceu ao art. 37, caput, o princípio da "eficiência”, consolidou-se a legitimidade da fiscalização alcançar níveis nunca antes imagináveis.

A economicidade, segundo Régis Fernandes de Oliveira (2013, p. 94):

diz respeito a se saber se foi obtida a melhor proposta para a efetuação da despesa pública, isto é, se o caminho perseguido foi o melhor e mais amplo, para chegar-se à despesa e se ela fez-se com modicidade, dentro da equação custo-benefício.

E Ricardo Lobo Torres (1991, p. 37-44) ensina que "o conceito de economicidade, originário da linguagem dos economistas, corresponde, no discurso jurídico, ao de justiça.”. O que corresponderia "na eficiência na gestão financeira e na execução orçamentária, consubstanciada na minimização de custos e gastos públicos e na maximização da receita e da arrecadação", ou seja, no controle do custo-benefício, consubstanciada "na adequação entre receita e despesa, de modo que o cidadão não seja obrigado a fazer maior sacrifício e pagar mais impostos para obter bens e serviços que estão disponíveis no mercado a menor preço”.

Já a eficiência inserida no texto constitucional parametrizou o aspecto gerencial na fiscalização da gestão, indo além da noção de eficácia e efetividade. Assim, se por um lado o princípio da eficiência obriga a Administração Pública a reorganizá-la e a reestrutura-la para aumentar sua produtividade com qualidade, racionalizando seus procedimentos para torna-la mais ágil e competitiva, por outro, regula a atuação dos agentes públicos na busca do melhor desempenho possível para que os melhores resultados sejam atingidos.

Hely Lopes Meirelles (2016, p.62) ensina que:

dever de eficiência é o que se impõe a todo agente público de realizar suas atribuições com presteza, perfeição e rendimento funcional. É o mais moderno princípio da função administrativa, que já não se contenta em ser desempenhada apenas com legalidade, exigindo resultados positivos para serviço público e satisfatório atendimento das necessidades da comunidade e de seus membros. 
As vertentes econômica e de eficiência almejam a fraternidade no uso dos recursos disponíveis pelo Estado, colocando o Tribunal de Contas como guardião da utilização de uma complexa estrutura que deve servir aos anseios de uma sociedade inteira.

Nesse ponto, a função social dos Tribunais de Contas somente se concretiza quando do cumprimento de suas competências na busca pela aplicação de todos os princípios inerentes à Administração Pública. A verificação dos aspectos meramente legais e formais deixaram de ser a sua razão de existir dos Tribunais de Contas, cabendo-lhe transformar a previsão constitucional do princípio da eficiência, de uma categoria teórica para uma pragmática e concreta.

Portanto, os Tribunais de Contas não são a função social, mas sim possuem e cumprem uma função social na medida em que não são um fim em si mesmos. A função social consiste num núcleo vital e inerente a todas as ações humanas que pretendem atingir terceiros, como o Estado. Esse núcleo consiste no exercício do controle social quando o controle interno não é suficiente. Não que a necessidade de existir o controle seja pressuposto de ações de má-fé, mas, mesmo que de boa-fé, erros são cometidos, e a vigilância e a fiscalização precisam estar atentas, tanto para as más quanto para os atos eivados de boas intenções.

Estas considerações conduzem ao problema da compatibilidade dos conceitos de função e de direito subjetivo. Se o exercício da “função” é considerado um vínculo, o direito subjetivo constitui uma liberdade. Os Tribunais de Contas devem exercer suas funções constitucionais institucionais e que em tese, não possuem escolha, são obrigadas a proceder à fiscalização da arrecadação e do destino do dinheiro público. Mas a onipresença não é uma característica que lhe possa ser atribuída, e os mecanismos de que dispõe são limitados, de modo que, a conexão e a efetivação de suas funções deve procurar minimizar os efeitos do subjetivismo da escolha do que fiscalizar.

É preciso reconhecer que a Constituição Federal, ao atribuir aos Tribunais de Contas a função de fiscalização, também lhe concedeu o poder de determinar a correção das ações de Estado que acarretem prejuízo ou má aplicação do erário.

A presença dos Tribunais de Contas de maneira antecipada possibilita o acompanhamento de todas as fases do ciclo das Políticas Públicas. Desde a sua idealização, contribuindo com a discussão de sua construção com suas informações técnicas, passando pela própria execução dessas Políticas junto à população, e até mesmo na análise dos resultados 
obtidos, os Tribunais de Contas devem atuar pró-ativamente, na busca pela concretização de sua função social.

A adoção de medidas cautelares de natureza mandamental que proporcionam a correção imediata de irregularidades e ilegalidades, e a fiscalização concomitante são os instrumentos em que os Tribunais de Contas conseguem um maior alcance na Administração Pública por atingirem o centro da gestão administrativa e, principalmente, no transcurso da execução de suas atividades. Portanto, devem ser esses instrumentos cada vez mais difundidos e largamente utilizados.

E para maximização do aproveitamento desses instrumentos, devem os Tribunais de Contas servirem-se das modernas tecnologias e que contribuem para que a sua presença seja real e concomitante junto aos entes e órgãos fiscalizados.

É dessa maneira que o Controle Externo atingirá definitivamente a eficiência pedagógica junto à Administração Pública diminuindo sua carga de atuação no cumprimento da função punitiva (e que evidencia um excesso de fiscalização a posteriori), passando a atuar de maneira preventiva e concomitante, orientando e corrigindo os percalços que impedem o desenvolvimento das Políticas Públicas.

Portanto, para os Tribunais de Contas a função social é uma reserva de lei reforçada, pois lhe permite exercer o controle técnico (e não político) das ações da Administração Pública e julgar o exercício dos atos praticados que envolvam cifras estatais. A interpretação atual dos arts. 70 e 71 da Constituição Federal reclamam dos Tribunais de Contas o desenvolvimento de uma atividade que assegure o cumprimento de sua função social e que supera o controle meramente formal e documental, passando a se ocupar do processo administrativo como um todo, pois somente essa abrangência é capaz de se fazer compreender e controlar a eficiência dos atos de Administração Pública voltados às Políticas Públicas e que levem à paz e à satisfação das necessidades da população.

\section{Considerações finais}

Com o fortalecimento das competências dos Tribunais de Contas na Constituição Federal de 1988 o núcleo de suas atribuições de controle externo concentram-se em 2(dois) dispositivos, atribuindo a fiscalização contábil, financeira, orçamentária, operacional e 
patrimonial da União e das entidades da administração direta e indireta, quanto à legalidade, legitimidade, economicidade, aplicação das subvenções e renúncia de receitas; e impõe expressamente o dever de prestação de contas ao Tribunal de Contas a um rol extenso e abrangente de pessoas (art. 71), o que amplia o seu poder de fiscalização.

Todos os dispositivos constitucionais de que tratam das competências do Tribunal de Contas da União foram reproduzidos por simetria nas Constituições Estaduais aplicando-se aos Tribunais de Contas Estaduais, e nas Leis Orgânicas dos municípios que possuem Tribunais de Contas do Município ou dos Municípios.

Ainda na Constituição Federal de 1988 temos no núcleo dos aspectos passíveis de fiscalização, a fixação do elemento “economicidade”, que já possibilitou uma atuação maior dos Tribunais de Contas. Anterior à Constituição de 1988 a adequação dos fatos à norma limitava-se ao aspecto de legalidade, restringindo-se aos aspectos formais dos atos administrativos. E com a Emenda Constitucional n. 19, de 04 de junho de 1988, onde fora acrescido ao art. 37, caput, o princípio da “eficiência” como princípio da Administração Pública, consolidou-se uma legitimidade à fiscalização verticalizada do controle externo e que se estende até mesmo à verificação da própria gestão administrativa.

Se antes da Constituição Federal de 1988, a Instituição Tribunal de Contas cumpria uma função fiscalizatória burocrática; nessa nova era democrática surgida ao final do século $\mathrm{XX}$, tem ele uma função fiscalizatória administrativa e social, que tende a ser mais preventiva que repressiva, mais concomitante que a posteriori, mais pedagógica que punitiva, mais presente, mais atuante e mais moderna.

Os Tribunais de Contas, sendo capazes de detectar com agilidade as irregularidades na aplicação do dinheiro público, também com rapidez e preventivamente, exigir a reparação de qualquer desvio que comprometa a boa gestão pública ou que coloque em risco a população nas diversas áreas da atuação governamental estará cumprindo sua função social que, segundo a Constituição Federal, constitui-se de uma reserva de lei reforçada, pois lhe permite exercer o controle técnico (e não político) das ações da Administração Pública e julgar o exercício dos atos praticados que envolvam aplicação do dinheiro, bens e valores públicos, principalmente sob o prisma da economicidade e eficiência.

A interpretação dos arts. 70 e 71 da Constituição Federal de 1998 e das Constituições Estaduais e Leis Orgânicas Municipais reclamam dos Tribunais de Contas o desenvolvimento 
de uma atividade que assegure o cumprimento de sua função social, superando o controle meramente formal e documental, e passando a se ocupar da gestão administrativa, pois somente essa abrangência é capaz de se fazer compreender e controlar a eficiência dos atos de Administração Pública e, por consequência direta, da eficiência na implantação, manutenção e desenvolvimento das Políticas Públicas e devem levar à paz social e à satisfação das necessidades da população, não apenas de maneira mínima, mas satisfatória para se fazer cumprir o fundamento da dignidade da pessoa humana.

\section{Referências}

BARROS, Lucivaldo Vasconcelos. TCU: Presença na história nacional. In: Brasil. Tribunal de Contas da União. Prêmio Serzedello Corrêa 1998: Monografias Vencedoras. Brasília: TCU, Instituto Serzedello Corrêa, 1999.

BEZERRA, Paulo Sério Alves e outros. O Controle externo das contas públicas: tendências atuais. Disponível em: <http: www.portal2.tcu.gov.br/portal/p/s/portal/docs/2055730>. Acesso em: 15 mar. 2018.

CARVALHO FILHO, José dos Santos. Manual de direito administrativo. 25.ed. São Paulo: Atlas, 2012.

CASTRO, José Ricardo Parreira de. Ativismo de contas. Rio de Janeiro: JAM Jurídica, 2015.

FERNANDES, Jorge Ulisses Jacoby. Tribunais de Contas do Brasil. Belo Horizonte: Fórum, 2012.

FIGUEIREDO, Lúcia Valle et al. Ministério Público partícipe do Tribunal de Contas e controle substancial ou de mérito. Revista de Direito Público. São Paulo. v. 25, n. 99, jul/set 1991.

GUERRA, Evando Martins. Direito financeiro e controle da atividade financeira estatal. 3. ed. Belo Horizonte: Fórum, 2012.

LENZA, Pedro. Direito constitucional esquematizado. 12.ed. rev., atual. e ampl. São Paulo: Saraiva, 2008.

MEIRELLES, Hely Lopes. Direito administrativo brasileiro. 42. ed. São Paulo: Malheiros, 2016.

MELLO, Celso Antônio Bandeira de. Curso de direito administrativo. 29. ed. São Paulo: Malheiros, 2012. 
MILESKI, Helio Saul. O Controle da gestão pública. In: COSTA, Luiz Bernardo Dias (Org.). Tribunal de Contas: evolução e principais atribuições no Estado Democrático de Direito. Belo Horizonte: Fórum, 2006.

OLIVEIRA, Régis Fernandes de. Curso de direito financeiro. 5. ed. São Paulo: RT, 2013.

SANTOS, Jair Lima. Tribunal de Contas da União \& controles estatal e social da administração pública. Curitiba: Juruá, 2005.

TORRES, Ricardo Lobo. O Tribunal de Contas e o controle da legalidade, economicidade e legitimidade. Rio de Janeiro, Revista do TCE/RJ, n. 22, jul./1991.

ZYMLER. Benjamin. Direito administrativo e controle. Belo Horizonte: Fórum, 2006.

ZYMLER, Benjamin; ALMEIDA, Guilherme Henrique De La Rocque. O controle externo das concessões de serviços públicos e das parcerias público-privadas. Belo Horizonte: Fórum, 2005. 